\title{
Retail Energy Management in Electricity Markets: Structure, Challenges and Economic Aspects- a Review
}

\author{
Hessam Golmohamadi ${ }^{1} \cdot$ Reza Keypour $^{1}$
}

Received: 8 May 2017 / Accepted: 4 November 2017 / Published online: 18 November 2017

(C) Springer Nature Singapore Pte Ltd. 2017

\begin{abstract}
In the rapidly growing global energy consumption, electrical energy plays the important role. Environmental concerns about air pollution, fossil fuels depletion and energy crisis have led policy makers of energy systems to increase the portion of electricity in the energy portfolio. On the other hand, economic crises, especially in recent years, have increased the electricity price. With decreased purchasing power, end-use consumers are encouraged to participate in Demand Side Management (DSM) programs, e.g. Demand Response Programs (DRPs), to decrease their electricity bills. In such situation, retail energy management attracts attention in both development and improvement. This paper reviews the concept of retail energy management in modern structure of electricity markets. The objectives of this study are: a) review techno-economic studies in the literature to identify the main structure of retail energy management; b) review the different retail market studies for assessing economic performance; c) present a comprehensive evaluation about the role of DRPs in retail energy management; d) carry out an extensive survey of optimization approaches, mathematical modeling and optimization software about the retail energy management. This paper provides a template for market participants to optimize energy management in the retail side of electricity markets. The proposed structure encourages the efficient development of retail electricity market while eliminating
\end{abstract}

Reza Keypour

rkeypour@semnan.ac.ir

Hessam Golmohamadi

hessam@semnan.ac.ir

1 Faculty of Electrical and Computer Engineering, Semnan University, Semnan, Iran the potential for economic inefficiencies through complete modeling of retail electricity market.

Keywords Energy management - Demand response · Retailer · Electricity market · Uncertainty

$\begin{array}{ll}\text { Abbreviations } \\ \text { RER } & \text { Renewable Energy Resource } \\ \text { MG } & \text { Micro Grid } \\ \text { VPP } & \text { Virtual Power Plant } \\ \text { SG } & \text { Smart Grid } \\ \text { DG } & \text { Distributed Generation } \\ \text { WPP } & \text { Wind Power Producer } \\ \text { PHEV } & \text { Plug-In Hybrid Electric Vehicles } \\ \text { DRP } & \text { Demand Response Providers } \\ \text { CFaR } & \text { Cash Flow At Risk } \\ \text { GAMS } & \text { General Algebraic Modeling System } \\ \text { MATLAB } & \text { Matrix Laboratory } \\ \text { DRExM } & \text { Demand Response Exchange Market } \\ \text { RM } & \text { Reserve Market } \\ \text { EM } & \text { Energy Management } \\ \text { MT } & \text { Micro Turbine } \\ \text { FC } & \text { Fuel Cell } \\ \text { PTR } & \text { Price-Taker Retailer } \\ \text { RTM } & \text { Real Time Market } \\ \text { DAM } & \text { Day-Ahead Market } \\ \text { IDM } & \text { Intraday Market } \\ \text { FM } & \text { Future Market } \\ \text { ARIMA } & \text { Auto Regressive Integrated Moving Average } \\ \text { VaR } & \text { Value-At-Risk } \\ \text { CVaR } & \text { Conditional Value-At-Risk } \\ \text { RAROK } & \text { Risk Adjusted Return On Capital } \\ \text { CHP } & \text { Combined Heat and Power } \\ \text { DER } & \text { Distributed Energy Resources } \\ \text { MSF } & \text { Market Share Function } \\ \text { IGDP } & \text { Information Gap Decision Theory } \\ \text { GA } & \text { Genetic Algorithm } \\ & \end{array}$


PSO Particle Swarm Optimization

LMP Locational Marginal Pricing

ETC Electrical/Thermal/Cooling demand

PMR Price-Maker Retailer

\section{Introduction}

In the restructured electricity markets, retailers are profitbased entities which purchase electricity from wholesale market with volatile price and sell it to the consumers with specified tariff $[1,2]$. Owing to the uncertain nature of pool market price and the price fluctuation in the pool markets, uncertainty modeling is one of the main challenges of retailers. In addition, inherent uncertainty of clients' consumption in the power system increases the complexity of problem [3]. Retailers can procure the consumers' electricity demand from different resources: (1) self-generating facilities (2) market contracts and (3) wholesale markets.

\section{Literature Review on Fundamentals of Retail Electricity Market}

Conventional self-generating facilities, including gasfired/diesel engines, hydro turbines and energy storages are dispatchable resources with deterministic power output. It means that there is no uncertainty in the power output of these Distributed Generations (DG). Conventional DGs are appropriate resources for retailers to hedge against the uncertainties associated with electricity price and clients' consumption. On the other hand, Renewable Energy Resources (RER) as new self-generating facilities, including wind turbines and solar photovoltaic sites, are not dispatchable power resources. It means that there is a great deal of uncertainty in the power output of these resources. Due to uncertain nature of renewable energy resources, integration of them into power systems poses major challenges to the retail electricity market [4].

Regarding market contracts, retailers have access to different kinds of contracts to hedge against the electricity price uncertainty. Forward contracts, bilateral contracts, future contracts, call option, swing contracts and contracts for difference are the most common contracts in retail markets [5]. In addition, different trading floors of the wholesale electricity market, including Day-Ahead Market (DAM), intraday/adjustment market and real time/balancing/spot market, are used by retailers for electrical energy procurement [6].

Integration RERs to the electricity market poses major challenges to the power system. The control, operation and regulation of an electricity market that includes stochastic renewable production facilities are actually different than those of a market with only deterministic production facilities. The situation may be deteriorated when a retailer (which has a great deal of uncertainty) intends to procure some parts of its obligated energy through stochastic renewable resources. Considering the increased use of RERs in the last decades, many studies investigate new approaches to integrate the RERs into the electricity market. Roughly speaking, there are three main attitudes for integrating the RERs into the electricity market as follows [7]:

1. Wind generation is managed through the electricity market as a negative demand. The Wind Power Producers (WPP) are paid a regulated tariff releasing from determining bidding strategy and generation plan.

2. Wind producers participate in electricity market. They are paid a clearing price of electricity market plus a subsidy which is intended to strengthen the competitiveness of wind producers in the electricity market.

3. According to a pure competitive rationale, wind producers must bear the burden of the market as any other market participant [8]. Consequently, this situation is achieved by eliminating the subsidies in the previous point.

In the modern structure of electricity market, the advent of new profit-based entities, e.g. Demand Response Providers (DRP) [9] and Plug-in Hybrid Electric Vehicles Aggregators (PHEVA) [10] raises topical issues in retail market studies. Regarding the newly emerged entities, multi-agent model of power systems makes it possible to study different agents in an oligopoly electricity market and investigate new ways to develop effective strategies in retail market studies.

\section{Gaps in the Literature and the Contribution}

In the literature, many researches exist that study retail energy management in the competitive structure of electricity market. To the best of our knowledge, no comprehensive review for the retail energy management has been reported in the literature. Therefore, the contribution of this paper can be stated as follows:

(1) Providing a comprehensive review of technical and economic aspects of retail energy management in modern structure of electricity market.

(2) Presenting an extensive survey of mathematical formulation of the retail problem in terms of components, uncertainties, mathematical modeling, optimization methodologies and risk analysis.

(3) Introducing the concept of retail energy management in presence of newly emerged entities, including DRPs and PHEVAs.

This paper concentrates mostly on retail energy management strategies in the future structure of electricity markets emphasizing the integration of newly emerged entities to retail electricity markets. For this reason, first of all, a 
fundamental review of retail problem in the electricity market is presented. In this section, an extensive review of retail market, including structure, components and mathematical programming, is conducted. Secondly, the impacts of newly emerged entities, e.g. demand response providers and PHEV aggregators, in the retail market studies are investigated. To sum up, the main aim is to address the economic and technical aspects of retail energy management in the future structure of competitive electricity market emphasizing increased use of sustainable energies.

The remainder of the paper is organized as follows. "Retail Electricity Market" presents the economic aspects of retail energy management in the competitive structure of electricity market. We develop the model for both pricemaker and price-taker retailers. Moreover, pure and monopolistic competition in the form of perfect and imperfect retail electricity markets is presented. In "Fundamentals of Energy Management in Retail Market", we provide an extensive review of retail problem in terms of mathematical formulation. In this section, different parts of mathematical formulation for the retail problem are presented. "Retail Energy Management in Presence of New Emerged Entities" introduces the concept of retail energy management in presence of newly emerged entities, including DRPs and PHEVAs, which can be an interesting subject for future research studies.

\section{Retail Electricity Market}

Retailers are profit-based entities which purchase electricity from wholesale market with variable price and sell it to the end-use consumers with fixed tariff. The main aim of retailers is to make more profit in the electricity market reducing the financial risk of participation in the wholesale market. To achieve the aim, retailers should devise their plans for two problems: (1) plan of purchasing electricity from the wholesale market (2) plan of selling electricity in the retail market. Figure 1 describes the different sources of energy procurement in the retail electricity market.

\section{Energy Management in Retail Electricity Market}

The wholesale electricity trading environment is supplied by large-scale production facilities, i.e. conventional (thermal) generation units [11], renewable resources [12], aggregated DGs and storage devices [13]. The retailers can procure electrical energy in the wholesale electricity market through two different resources: (1) wholesale markets and (2) wholesale contracts. Considering the wholesale market, Day-ahead Market (DAM) [14-28], Real Time Market (RTM) [17-29], Reserve Market (RM) [15, 21, 22] and Intraday Market (IDM) [20] are the most common markets used by retailers to purchase their obligated energy. Moreover, regarding the wholesale contracts, future contracts [17, $26,29]$, forward contracts $[16,18,23,30]$, call option [23, $30]$ and swing contracts $[25,28]$ are typically used in different studies of retail market. In addition to the large-scale power production facilities which participate in the wholesale market, some retailers prefer to procure some parts of their electrical energy through bilateral contracts signed with small-scale power generators. In this regard, intermittent power production facilities, i.e. RERs, may increase the complexity of retail problem due to the uncertain characteristic of output power $[14,32,36]$. On the other hand, some retailers prefer to procure their obligated energy from deterministic power production units, e.g. gas fired/diesel engines, to hedge against the uncertainties associated with electricity price and clients' consumption [16, 23, 30, 31].

Owing to the recent advancements in electrical power networks, new entities, including DR providers [37] and PHEV aggregators [38], emerged to increase the efficiency of power systems. Demand response is defined as the changes in electric usage by end-use customers from their normal consumption patterns in response to changes in the price of electricity over time, or to incentive payments designed to induce lower electricity use at times of high wholesale market prices or when system reliability is jeopardized [39]. In order to coordinate different DR programs, DR providers [32] emerged in the smart structure of power system. DR providers are entities which modify the consumption pattern of end-use consumers through DR programs. Generally, DR programs are divided into two main categories [37, 40]: (1) price-based DR programs (2) incentive/event based DR programs.

Regarding the price-based DR programs, DR is implemented through approved utility tariffs or contractual agreements in electricity markets according to which the price of electrical energy varies over time in order to encourage customers to adjust their consumption patterns [37]. These programs are typically used to determine the consumption tariff for end-use consumers [17, 19, 23, 31]. Time of Use (TOU) [41], Critical Peak Pricing (CPP) [42], Extreme Day Pricing (EDP) and Real Time Pricing (RTP) [43] are the most common DR programs which are used as retail pricing schemes. In the incentive based DR programs, a bonus financial scheme is considered as a reward for customers to reduce their electric loads upon request or for giving the program administrator some level of control over the customer's electrical equipment [37]. These programs are mainly used by DR providers to increase the efficiency of power system in term of cost and reliability. In addition to DR programs, voluntary and mandatory load curtailment programs are proposed in some studies to increase the efficiency of retail market $[14,23]$. Demand response providers can aggregate different DR programs to reduce the demand 
Fig. 1 Structure of electricity market from viewpoint of retailers

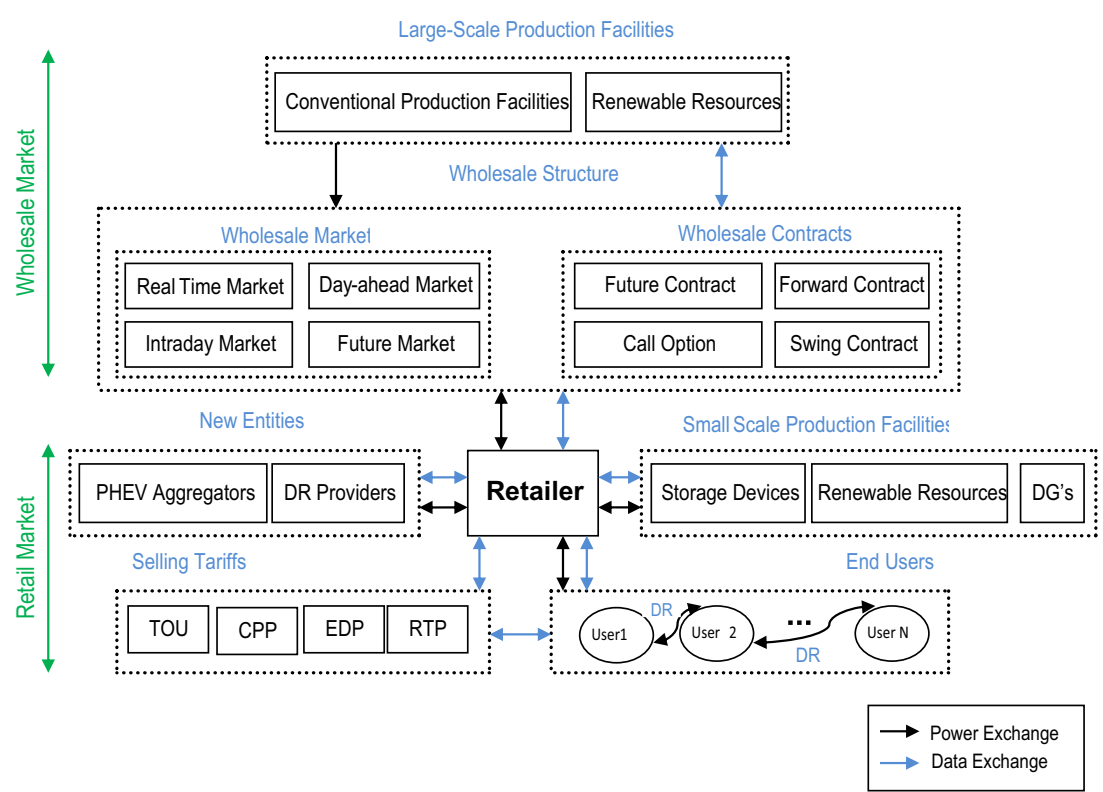

level of retailers when the wholesale electricity price is high. Therefore, these entities can help retailers to optimize their procurement costs.

PHEV aggregators are one of the new market players which coordinate DR programs for PHEVs as special demands [44]. The main aim of PHEV aggregators is to enhance the power system stability and increase the social welfare through reducing electricity price. Regarding the retail market, PHEV aggregators can coordinate charging and discharging programs to reduce the procurement cost of retailers in the competitive electricity market.

To sum up, retailers are able to procure their obligated energy through two different sources: (1) real power production facilities, e.g. conventional and renewable generation units and (2) virtual power production facilities, e.g. DRPs and PHEVAs.

Table 1 summarizes different sources of energy supply for power system retailers. Regarding the real power production facilities, the retailers can procure their obligated energy from the following resources:

(1) Wholesale market: the wholesale electricity market consists of different types of electricity markets, including, DAM, IDM, RTM and RM.

(2) Wholesale contract: the retailers can procure some parts of their obligated energy from the contracts signed in the wholesale market. Forward, future, call option and swing contracts are the most common contracts which are typically used in the retail electricity market.

(3) Renewable energy resources: distributed wind generation, photovoltaic solar sites and hydroelectric power generation are the most important renewable energy resources which are used to procure the required energy in the retail side of electricity market.

(4) Conventional distributed generation: thermal distributed generation can be interpreted as a deterministic power generation for a retailer to hedge against the uncertainties associated with volatile electricity price and intermittent power output of RERs.

(5) Storage devices: energy storage systems can be used by the retailers to be charged in lower prices during off-peak periods and be discharged in higher prices during peak periods. It is evident that the presence of ESSs can flatten the profile of electricity price and help the retailer to propose competitive prices to the end-use consumers.

Considering the virtual power production facilities, new market players, e.g. DRPs and PHEVAs, can supply some parts of the retailers' obligated energy. The DRPs can manage the consumption patterns of responsive demands during peak and off-peak periods. These entities can help the retailers to flatten the profile of electricity price/demand through several Demand Side Management (DSM) programs. In addition, the PHEVA is a financial agent in the electricity markets which can manage charge $\backslash$ discharge pattern of its consumers (PEVs). This agent can help the retailers to purchase (sell) deficit (surplus) of their energy from (to) the aggregated PEVs. The interaction of retail agents and PHEVAs can be an interesting issue for the future researches.

To sum up, a brief survey of energy supply resources for the electricity retailers are presented in the Table 1. 


\section{Price-Maker and Price-Taker Retailers}

In the literature about the energy management in retail electricity markets, there are many different research studies which consider the retailers as a price-taker agent [21-29]. Price-taker retailers (PTR) and price-maker retailers (PMR) are exposed to different sources of uncertainty. Regarding the price-taker agent, the retailers usually aim to maximize the profit considering the uncertainties associated with electricity price and clients' consumption [17]. Price-maker retailers, which are addressed in energy management problems occasionally [20], are exposed to more uncertainty, i.e. the unforeseen behavior of other price-maker retailers. This kind of uncertainty is due to the fact that a strategic retailer should estimate the behavior of other competing retailers, e.g. bidding strategies, in the competitive structure of electricity market to stay in business. Indeed, in the EM problems with price-maker retailers, the influence of different electricity bidding strategies on the electricity market price should be taken into account by reproducing the clearing process with the residual supply curves [20]. The additional process may increase the calculation and time burden of the EM problem. Figure 2 depicts a schematic diagram about the role of PTR/PMR in an electricity market. Based on the figure, we can say that a PTR should participate in the electricity market providing one-way bidding strategies. On the contrary, a PMR should estimate the behavior of other market participants providing two-way bidding strategies.

\section{Monopolistic and Pure Competition in Retail Market}

The main aim of deregulation in power systems is to provide an increasingly competitive environment for all market participants. To achieve this aim, market players can participate in different floors of electricity market. Market power is one of the serious challenges which may decrease the social welfare of electricity markets. A general approach to prevent from exercising market power by strategic players is to increase competition among market participants. In the literature about the retail energy management, many research studies have addressed the retail electricity market with monopolistic competition (imperfect market) [14-17, 31-33]. In these studies, only one retailer is considered for the problem. The logical reason for this structure is to avoid increasing the complexity of the problem. On the contrary, instead of monopolistic competition, there is pure competition (perfect market) in some research studies. In these studies, two or more retailers are considered in the problem to enhance the retailers' competitiveness [23, 29]. In such structure, each retailer is pressured to attract more consumers in the retail electricity market. It is evident that if a retailer cannot propose a competitive price to the clients, it 


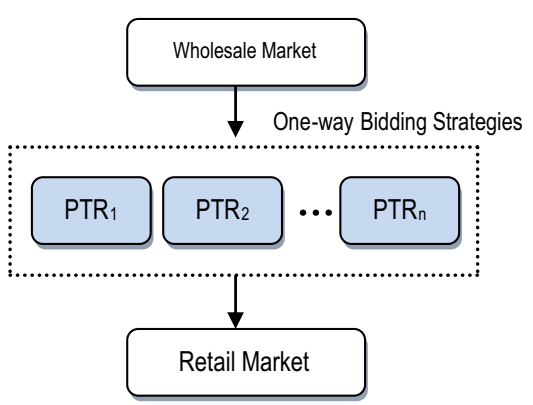

(a)

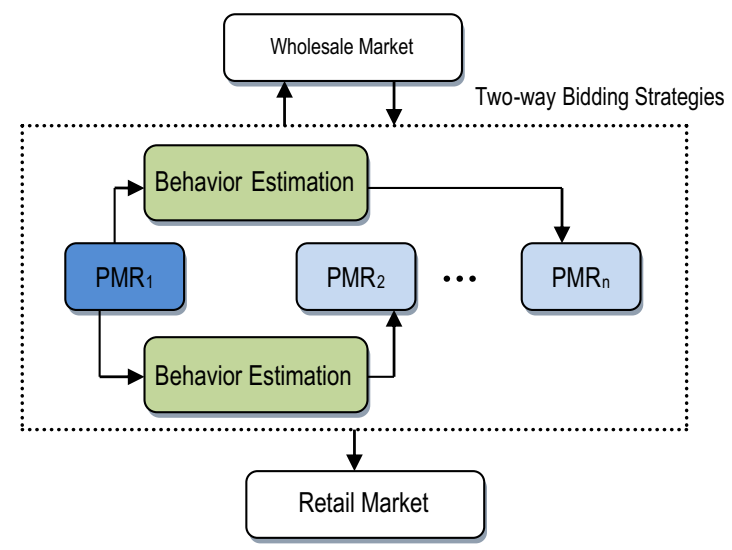

(b)

Fig. 2 Participation of a price-taker retailer b price-maker retailer (from viewpoint of $\mathrm{PMR}_{1}$ ) in the electricity market

may lose some big customers. Paper [30] uses Market Share Function (MSF) to model pricing strategies of competing retailers. In this structure, each retailer generates a price distribution, i.e. equilibrium prices are defined by a probability density function, indicating the range of prices that the retailer may charge. The probability density function according to which the retailer sets its equilibrium prices is defined as the market share function [30].

\section{Fundamentals of Energy Management in Retail Market}

In this section, a survey of technical structure of retail problem is presented. The aim is to find out how a problem in retail electricity market is formulated and simulated in terms of technical and mathematical structures.

\section{Structure and Components}

Retailers are profit-based entities which aim to maximize the profit under a controlled degree of risk. Considering the fundamentals of retail electricity market, a retail problem consists of two main parts: (1) purchasing electricity from the wholesale market (2) selling electricity to the end-use consumers.

Regarding the wholesale contracts, retailers should make decision about the kind and demand level of the contracts. In the wholesale market, e.g. day-ahead market, volatile electricity price may increase the complexity of the problem. Moreover, elastic/uncertain load characteristics of the end-use consumers pose major challenges to the retailers. Therefore, stochastic variables play an important role in formulation of the retail problem.

Because of the stochastic behavior of the main variables in a retail problem, deterministic programming is not an effective method to solve the problem. For this reason, a stochastic programming approach is needed. In the stochastic programming, a set of scenarios is generated to parameterize the stochastic behavior of the main variables. It is evident that the stochastic programming leads to a series of optimization measures with a degree of risk. As a result, a risk analysis method is considered as one of the main parts of the stochastic programming approach, especially in a retail electricity market. Obviously, the stochastic programming is a mathematical framework for modeling the optimization problems that involve uncertainty. Modeling the mathematical problem, an optimization approach is needed to solve the problem. In order to provide a tractable model for the problem, a computer-based software with appropriate solver is needed.

To sum up, the key components of the retail problem in terms of technical and mathematical structures are described as follows:

(1) Type of uncertainties

(2) Mathematical modeling

(3) Optimization solution

(4) Scenario generation approach

(5) Risk analysis

(6) Solver and software

In the next subsections, the aforementioned components are illustrated.

\section{Uncertainties}

Electricity price and clients' consumption are the key uncertain variables in the retail problem [17, 23, 28-34]. Volatile electricity price in the electricity market, e.g. day-ahead and real time markets, poses major challenges to the retailers. Regarding the uncertainty associated with the electricity price, different trading floors are considered in retail 
market studies. Day-ahead market [14], reserve market [21, 22], regulation market [24] and real time market [25] are the most important trading floors in the retail market studies.

Generally, the more uncertain variables are considered, the more complex problem is created. Some research studies address the uncertainties associated with the power output of renewable energy resources, e.g. wind turbines [32] and solar energy systems [36]. Considering pure competition in the retail market, the stochastic behavior of other competing retailers is considered as a key uncertain variable [29]. In order to estimate the behavior of retailers in a competitive electricity market, a Market Share Function (MSF) is devised to show the behavior of competing retailers toward electricity price variations [30]. Table 2 describes the most important uncertain variables which are considered in research studies of the retail problem. As the table reveals, electricity price and load level are the most important uncertain variables which are typically addressed in the retail studies. In addition, due to the integration of renewable energies to the power systems, especially in recent years, many research studies discuss the use of RERs in the retail electricity market in the form of self-generation facilities. In this regard, the intermittent power output of RERs can be interpreted as a main uncertain variable which can affect the retail strategies. In a perfect electricity market with pure competition, the retailer should forecast the behavior of other competing retailers to propose a competitive electricity price. This approach can help the retailer to preserve and increase its customers by optimizing its tariffs. Considering the newly emerged entities, e.g. DRPs and PHEVAs, the complexity of the problem may be increased. In this situation, the uncertainties associated with PEVs and responsive demands are added to the retail problem. Additional illustrations about the role of DRPs and PHEVAs in retail electricity market are presented in "Retail Energy Management in Presence of New Emerged Entities". In order to conduct a comprehensive study about the retail energy management, a complete set of uncertainties which affects the retail strategies should be discussed in the problem. In conclusion, the results are reviewed in Table 2.

\section{Mathematical Modeling}

Decisions in the retail market need to be made with lack of perfect information; therefore, it motivates policy makers of the retail market to use stochastic programming approach in their decision making processes. The most common way to model the problem with uncertain variables is the stochastic programming. Regarding the retail problem, many research studies use stochastic programming approach to model the problem mathematically [14-29]. Instead of the stochastic programming, some papers, especially in recent years, have concentrated on Information Gap Decision Theory (IGDT) [16] and robust optimization approach [31] to model the retail problem. A distinguishing feature of the robust optimization is that the approach can reduce the computational time burden of the retail problem considerably in contrast to the stochastic programming approach [31].

First of all, in the stochastic programming approach, the number of stages is a key feature. Modeling the retail problem, the number of stages (e.g. single-stage, twostage, three-stage and multi-stage stochastic programming) depends on the number of decision making procedures during electricity market performance. In the problem with two supply markets, e.g. day-ahead and real time markets, the stochastic programming is converted into a two-stage approach [14]. However, considering more trading floors, e.g. forward contract, day-ahead market, intraday market and real time market, the stochastic programming is converted into a multi-stage approach [28]. It is worth mentioning that in the stochastic programming with recourse, retailers are able to take corrective measures in each stage of the stochastic programming (correspond to each trading floors of the retail market). Modeling the problem with

Table 2 The most important uncertain variables in retail market studies

\begin{tabular}{ll}
\hline Type Of Uncertainty & Description \\
\hline Electricity price & - The most important uncertainty in the retail problem. \\
& - It is composed of different market trading floors, e.g. electricity price of DAM, IDM and RTM. \\
& - The uncertain load characteristic of the end-use consumers is one of the most important \\
Load level & - The elastic behavior of consumers toward the electricity price variations increases the \\
& complexity of the retail problem. \\
& - Wind and solar power are the most important uncertain variables for those retailers who \\
& use renewable energy resources in their energy portfolio. \\
Renewable output power & - Stochastic behavior of competing retailers plays crucial role in perfect markets with pure competition. \\
& - The problem can be more complex when the retailers are price-maker agents. \\
Behavior of retailers & - In the retail problem with considering the PHEVA, the retail strategies can be deeply \\
& affected by the stochastic behavior of PHEVs.
\end{tabular}


more than three stages, the problem may be less tractable than expected. Figure 3 shows a schematic diagram about the three-stage stochastic programming with recourse for 24-hour scheduling in the retail electricity market.

Secondly, IGDT is based on quantitative models and provides numerical decision-support assessment; however, its underlying theory is not a closed computational methodology. IGDT method maximizes the horizon of uncertainty and finds a solution that guarantees a certain expectation for the objective. This method has practical advantage over scenario-based approaches, i.e. stochastic programming. In the case of retail energy management, an IGDT-based model determines optimal schedules in order to achieve a target profit, whereas scenario-based methods find optimal schedules based on a limited number of possible scenarios. In addition, unlike scenario-based models, IGDT-based methods guarantee a predefined level of profit for the retailer. In approaches where the stochastic variables are modeled using probability theories, distribution functions are assumed and employed to model and measure trading risk. In contrast, in the IGDT approach, neither a particular assumption about the nature of the uncertain parameter is required nor any pre-assumption on the size of uncertainty is enforced [51].

Finally, in the robust optimization approach, the stochastic variables are characterized by the so-called uncertainty set, which the uncertain variables can take value in. Then, the objective function is optimized in the worst-case point of these sets. In paper [52], the aim is to determine the optimal retail strategies, especially determine the optimal selling electricity price, under worst-case realization of the wholesale market price uncertainty. In this paper, maximization of the retailer's profit for the worst-case realization of the wholesale price uncertainty is stated as a min-max problem. In paper [53], a robust optimization approach is presented for determining the day-ahead bidding strategies of a large-scale hybrid electric energy company. The max-min bi-level structure of the problem is converted to equivalent single-level optimization using Karush-KuhnTucker optimality conditions. Reference [54] presents a two-stage model for the energy pricing and dispatch problem faced by a smart grid retailer who plays the role of an intermediary agent between a wholesale market and enduse consumers. The problem is modeled using linear robust optimization approach and is transformed to a mixed integer linear program (MILP) by jointly using the Karush-KuhnTucker (KKT) condition and the duality theory.

\section{Optimization Solution}

Decision-making problems can be adequately formulated as optimization problems. Generally, if the input variables of the problem are deterministic, the optimal solution is found by using the optimization methods directly. On the other hand, in the problems with imperfect data, stochastic/robust approaches are needed to formulate the problem mathematically before using optimization methods.

Due to the different formulations of the retail problem, the mathematical structure of the problem can be in two different forms: (1) linear programming [18, 34] and (2) non-linear programming [20-22]. Linear objective functions are usually solved using classical (mathematical) optimization techniques, e.g. Benders Decomposition [18], Branch and Bound approach [23], Karush-Kuhn-Tucker condition [29] and Duality Theory [33]. The non-linear objective functions are divided into two different categories. In the first category, the complexity of the problem and constraints can be mitigated through mathematical reformulation of the problem [29]. In these studies, the non-linear structure of the problem can be transformed into a linear structure which is tractable and appropriate to be solved by using the traditional optimization techniques. In the second category, due to the non-linear nature of the problem and great technical complexity, the classical optimization
Fig. 3 Three-stage stochastic programming with recourse in the short term retail market

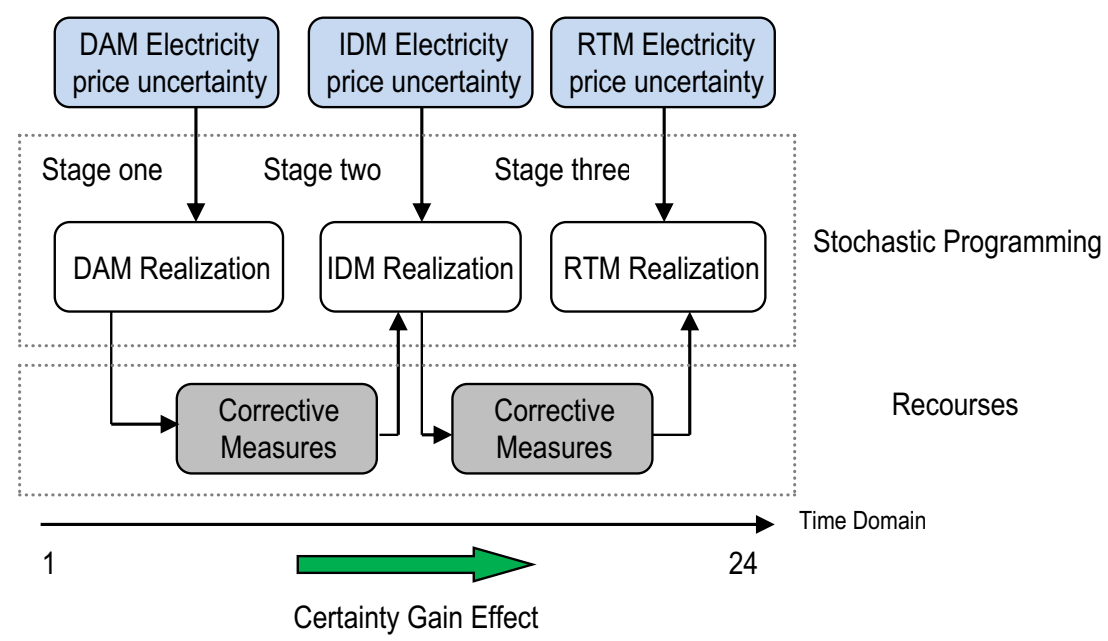


approaches are neglected and heuristic search algorithms, e.g. Genetic Algorithm (GA) [21, 22], Particle Swarm Optimization technique (PSO) [55] and Imperialist Competitive Algorithm (ICA) [55] are used to solve the problem.

Note that the complexity of the retail problem (from linearity or nonlinearity perspective) depends heavily on three following factors:

(1) The structure of retail market, e.g. the number of wholesale market floors and contracts.

(2) Type of uncertainties, especially the uncertainties associated with renewable energy resources.

(3) Type of competition, i.e. monopolistic or pure competition.

\section{Scenario Generation}

Considering the retail problem with uncertain variables, the probability distribution of input uncertain data can be approximated by a collection of plausible sets of input data with associated probabilities of occurrence which is called scenario. In order to generate scenarios for the retail problem with a great number of input data, a computationalbased scenario generation mechanism is needed. Auto Regressive Integrated Moving Average (ARIMA) is the most common mechanism to generate scenarios in the retail problems [23, 29, 30, 34]. ARIMA approach is based on time series and consists of three parts as Auto Regressive (AR), Integration (I) and Moving Average (MA) which makes it possible to measure the correlation between historical and forecasted data. Monte Carlo simulation approach is typically used in the studies which the retailer is equipped with the intermittent self-generation facilities. In [14, 19], the Monte Carlo simulation approach is used to forecast the hourly wind speed for the distributed wind generationowning retailer. In addition, Roulette wheel technique, which is based on the probable occurrence of stochastic variables, is used in some research studies to forecast the behavior of competing retailers [18]. Moment matching is another successful method to generate scenarios for the stochastic optimization [56]. This approach can be used for retail problems with lack of perfect data.

\section{Risk Analysis}

The aim of retail problems is to maximize (minimize) the retailer's profit (cost). Formulating the stochastic programming approach, non-desirable properties of profit/cost distribution function, e.g. the scenarios with high probability of low (high) profit (cost), can result in unfavorable outcomes for the retailers. In order to reduce the potential risk, a risk assessment approach is needed. Table 3 describes different risk assessment approaches in the literatures. However, some risk indices are more common among the electricity market studies. Regarding the economic properties of electricity markets, five risk assessment approaches are typically used in the retail problems as follows [57-65]:

(1) Variance

(2) Shortfall probability

(3) Expected shortage

(4) Value-at-Risk (VaR)

(5) Conditional Value-at-Risk (CVaR)

In addition, Risk Adjusted Return on Capital (RAROC) and Cash Flow at Risk $(\mathrm{CFaR})$ are the other important risk assessment approaches which are used by some energy service companies [26].

The shortfall probability is the risk that an investment's actual return will be less than the expected return, or, more properly, the return needed to meet one's investment goals. Regarding the expected shortage, the profit risk can be hedged by the simultaneously pursuing expected profit maximization and expected shortage minimization.

Considering the risk assessment approaches, VaR and $\mathrm{CVaR}$ are the most common risk indices in the retail studies $[17,18,28]$. It is worth mentioning that $\mathrm{VaR}$ does not control scenarios exceeding VaR whereas CVaR accounts for losses exceeding VaR. For this reason, CVaR is the most important risk assessment approach which is used in different studies of retail electricity market $[30,34]$. To sum up, the results are briefly surveyed in Table 3.
Table 3 Risk assessment approaches in different studies

\begin{tabular}{lllll}
\hline Studies & Risk index & Risk Index & Risk Value & Explanation \\
\hline$[57,58]$ & Variance & $\operatorname{Var}$ & $\operatorname{Var}(\mathrm{x})$ & $\mathrm{x}$ : variable \\
{$[59]$} & Shortfall probability & $\mathrm{SF}$ & $\mathrm{SF}(\eta, \mathrm{x})$ & $\eta$ : pre-fixed value \\
{$[60]$} & Expected shortage & $\mathrm{ES}$ & $\operatorname{ES}(\eta, \mathrm{x})$ & $\alpha$ : reliability level \\
{$[61]$} & Value-at-risk & $\operatorname{VaR}$ & $\operatorname{VaR}(\alpha, \mathrm{x})$ & \\
{$[62,63]$} & Conditional value-at-risk & $\mathrm{CVaR}$ & $\mathrm{CVaR}(\alpha, \mathrm{x})$ & \\
{$[64]$} & Risk adjusted return on capital & $\mathrm{RAROK}$ & - & \\
{$[65]$} & Cash flow at risk & $\mathrm{CFaR}$ & - & \\
\hline
\end{tabular}




\section{Solver and Software}

The energy management problem in retail market is usually simulated using two advanced commercial software, General Algebraic Modeling System (GAMS) and Matrix Laboratory (MATLAB). Based on the different formulations of the problem, different solvers are used to optimize the problem. CPLEX [14, 31, 32], DICOPT [15], CONOPT [17] and MOSEK [18] are the most common solvers which are used to find the optimized solution in the retail energy management studies. Besides, other commercial software, e.g. Dash Optimization Software Xpress, can be used to obtain optimized strategies in the retail problem [18].

In conclusion, Fig. 4 describes the most important technical features of the retail problem.

\section{Retail Energy Management in Presence of Newly Emerged Entities}

In spite of the conventional retailers, two kinds of new retailers emerged in the modern structure of electricity market. DRP and PHEVA are newly emerged entities which purchase energy from the wholesale market and sell to the end-use consumers. The main difference between the previously mentioned retailers (traditional retailers) and the newly emerged retailers is that the new retailers can sell energy only to the specific loads (smart loads and PEVs) while the traditional retailers are able to sell energy to the all end-use consumers.

In retail market studies, the traditional and newly emerged retailers can be discussed in the form of separate agents. However, integrating the retailers into a same agent, the social welfare of retail market participants increases.

Demand Response (DR) are defined by the U.S. Department of Energy (DOE) as the incentive payments designed to induce lower electricity use at times of high wholesale market prices or when system reliability is jeopardized [66]. Besides, Demand Response Providers (DRPs) are newly emerged form of retailers which aggregate DR resources of the multiple small customers [67] and can provide a single operating profile by deployment of Advanced Metering Infrastructure (AMI) for DR resources same as a generating unit [68].

In retail electricity markets, consumers can adjust their consumption according to the retailers' offers and incentives. In the technical literatures, different retail pricing schemes are proposed to encourage the end-use consumers to participate in demand response programs.

Generally, demand response programs are divided into two main categorizes: (1) price-based DR programs and (2) incentive based DR programs. Regarding the price-based DR programs, the programs are typically used to determine the consumption tariff for end-use consumers. TOU, CPP, EDP and RTP are the most common DR programs which are used as retail pricing schemes. In the incentive based DR programs, a bonus financial scheme is considered as a reward for customers to reduce their electric loads upon request or for giving the program administrator some level of control over the customer's electricity-using equipment. These programs are mainly divided into two main categorizes: (1) classical programs and (2) market-based programs. Classical DR programs include Direct Load Control programs and Interruptible/Curtailable Load programs. In these programs, participating customers receive participation payments, usually as a bill credit or discount rate, for their participation in the programs. Market based DR programs include Emergency DR Programs, Demand Bidding, Capacity Market, and the Ancillary services market. In these programs, participants are rewarded with money for their performance, depending on the amount of load reduction during critical conditions [69-75].
Fig. 4 The structure of retail problem from viewpoint of technical and mathematical features

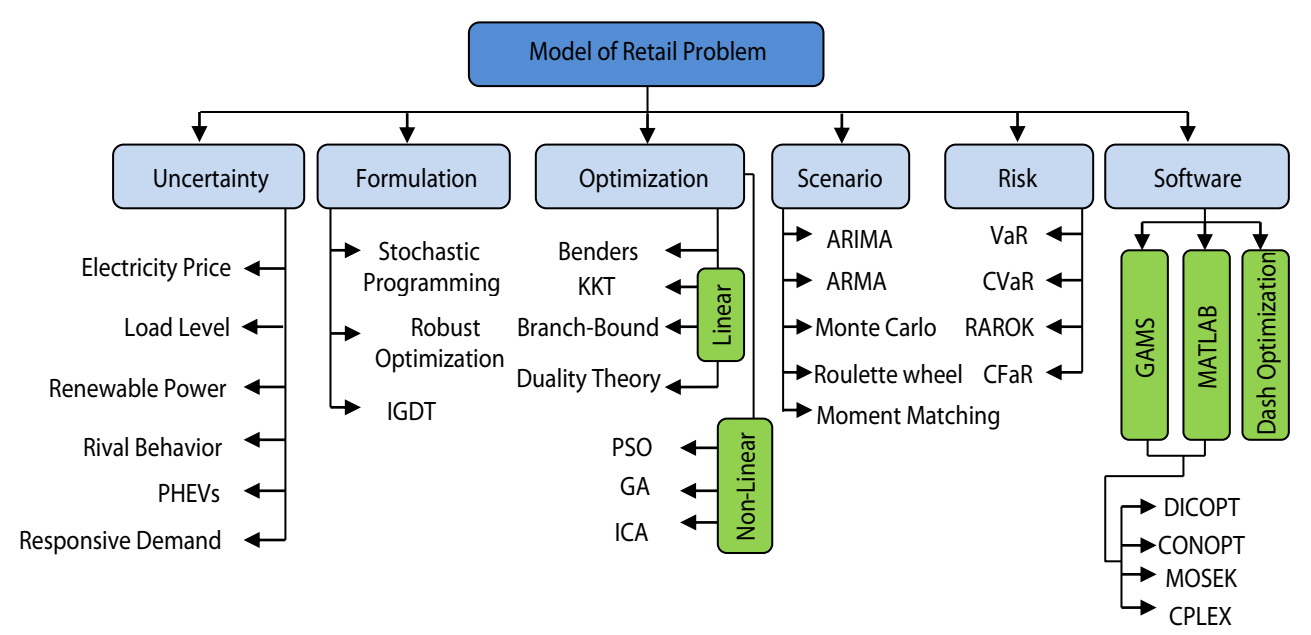


Table 4 DR programs in retail market studies

\begin{tabular}{llll}
\hline DR programs & Category & Description & Studies \\
\hline Incentive based DR programs (IBDRP) & Classical DRP & Direct control & {$[69]$} \\
& & Curtailable programs & {$[70]$} \\
& Market based DRP & Demand bidding & {$[71]$} \\
& & Emergency DR & {$[72]$} \\
Price based DR programs (PBDRP) & & Capacity market & {$[74]$} \\
& & Ancillary service markets & {$[75]$} \\
& TOU & {$[76,77]$} \\
& & CPP & {$[78,79]$} \\
& & ED-CPP & {$[80]$} \\
& & EDP & {$[80]$} \\
\hline
\end{tabular}

To sum up, Table 4 illustrates the most important demand response programs which are used in retail energy management studies.

Demand response providers can aggregate different DR programs to reduce the demand level of retailers when the wholesale electricity price is high. Therefore, this entity can help the retailers to optimize their procurement costs. Different studies have been concentrated on the use of demand response programs in the retail electricity market. Paper [52] determines the robust values of retail electricity price for end-use consumers considering their participation in DRPs. In order to model the behavior of consumers against the retail price, a combined demand function comprises of linear demand function, potential demand function, logarithmic demand function and exponential demand function is used. The results show that application of DR programs can reduce the retail electricity price offered to the consumers. In [83] dynamic retail pricing scheme is proposed to reduce peak loads and electricity bills for household consumers. In [84] the Stackelberg game-based DR algorithm is addressed to control the load of consumers in response to the retail price offered to the consumers through real time pricing scheme. Paper [85] uses DR programs in the retail side of an energy company to hedge against the uncertainty of wholesale market price. Paper [86] presents a novel retail market model in which elastic demands of consumers can be traded at flexible selling prices offered by a retailer. In this paper, the retailer offers a selling price and the response of elastic consumers toward the prices is investigated by using price-based DR programs In [87] an approach is proposed to determine day-ahead retail electricity price for elastic consumers. In this research, real time pricing and dynamic tariff are used to study the response of the clients toward the retail price. In [88] a price-based demand response program is proposed to facilitate the integration of Photovoltaic (PV) power in the distribution network and decrease the peak load of power network. In addition, the integration of PHEVs to the electricity market can be facilitated by using DRPs in retail side of electricity market [89].

In conclusion, use of demand response programs in the retail electricity market has many advantages for both electrical network and market participants. Regarding the electrical network, the use of demand response program can facilitate the integration of intermittent distributed energy resources and PHEVs to the electricity market. In fact, by giving the program administrator some level of control over the customer's electricity-using equipment, the power system operator is able to hedge against the uncertainties associated with output power of stochastic generation facilities. Considering the market participants, the retailer can
Fig. 5 The objectives of DRPs in retail electricity markets

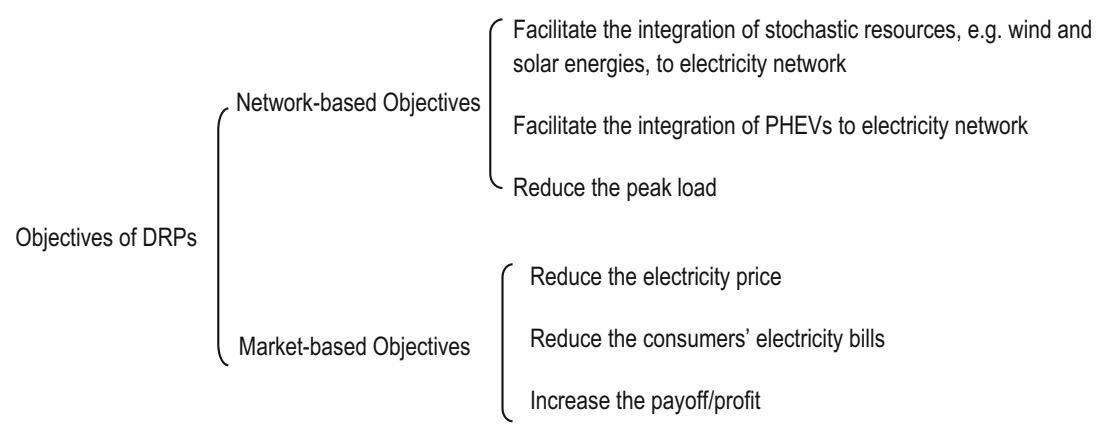




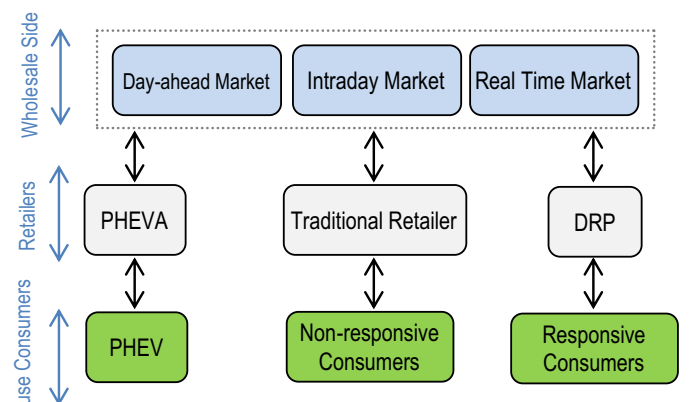

(a)

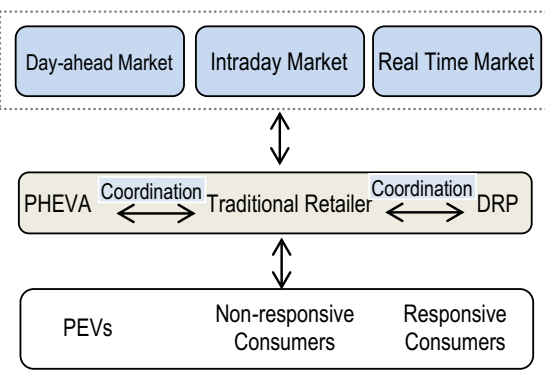

(b)

Fig. 6 The role of DRP and PHEVA in the multi-agent structure of retail market a individual form of retailers $\mathbf{b}$ integrated form of retailers

flatten the profile of electricity price offered to the consumers by using demand response programs. In addition, the end-use consumers can experience a significant reduction in their electricity bills through participating in demand response programs. To sum up, Fig. 5 surveys the most important objectives of DRPs in the retail side of electricity markets.

Plug-in hybrid electric vehicle aggregator is a financial agent which manages charge/discharge of PHEVs. In the retail electricity market, the PHEVA can help the retailer to flatten the profile of electrical demand through charging (discharging) the PHEVs in off-peak (peak) durations. Coordinating the operational plans of PHEVAs and retailers, the retailers are able to propose more competitive price to the consumers. As a result, the profit of retailer increases considerably. In addition, the end-use consumers pay lower cost for their electricity bills. Therefore, the social welfare of retail market participants, i.e. the retailer and customers, increases.

It is worth mentioning that the newly emerged entities, including DRP and PHEVA, can participate in retail electricity market individually. However, if the aforementioned entities are integrated with the traditional retailers, the social welfare of the electricity market increases. The reason is that providing coordination between operation strategies of PHEVs, responsive loads and traditional (non-responsive) loads can increase the efficiency of power system in terms of economic and technical aspects. To illustrate the problem, Fig. 6 illustrates the role of traditional retailers, DRPs and PHEVAs in a retail electricity market. In order to show the integration of the traditional retailers with the new retailers, the figure is depicted in two subfigures. As the figure reveals, the traditional retailer, DRP and PHEVA can participate in retail electricity market in the form of separate agents. However, in the multi-agent structure, the newly emerged entities can integrated with the traditional retailer to coordinate their operational programs.

\section{Conclusion}

This paper addressed the issue of retail energy management in modern structure of electricity markets emphasizing the increased use of Renewable Energy Resources (RERs). First of all, the fundamentals of retail electricity market were presented comprehensively. In this regard, structure, components, formulation and mathematical modeling of the retail problem in the electricity market were also explored. Moreover, the stochastic optimization problem, robust optimization and IGDT approach were discussed. The literature studies were analyzed from viewpoint of market trading floors and wholesale contracts. Dayahead market and real time market are commonly used in research studies of retail market. On the other hands, forward and future contracts attracted more attentions to hedge against the electricity price uncertainties. Finally, the retail energy management in presence of newly emerged entities, i.e. Demand Response Providers (DRPs) and Plugin Hybrid Electric Vehicle Aggregators (PHEVAs), was investigated.

To sum up, the conclusive findings of the research study can be stated as follows:

(1) Introducing the structure of retail energy management in terms of components, mathematical modeling and optimization methodologies.

(2) Find out how to provide a mathematical model to develop economic strategies in retail electricity market.

(3) Facilitating the integration of newly emerged entities, i.e. DRPs and PHEVAs, to the retail electricity market.

Considering the research studies, the following results were achieved:

(1) Electricity price and clients' consumption are the most important uncertain variables in retail studies. 
However, integrating RERs, DRPs and PHEVAs, the new uncertainties associated with intermittent output power, customer behavior and PEVs should be considered in the problem.

(2) Integration of RERs may increase the complexity of the retail problem. To hedge against the uncertainty associated with stochastic output power, implementation of demand response programs and thermal distributed generation were proposed.

(3) In the perfect market with pure competition, the retailers should forecast the behavior of other competing retailers to propose competitive tariff to the clients. By using an appropriate behavior forecasting method, the retailers can preserve and increase their customers.

(4) Modeling the retail electricity market completely, the retailer is able to flatten the profile of electricity price to maximize its profit.

The multiple studies were reviewed in the present paper to provide the most important knowledge for further developments in the retail electricity market. Important issues for research that require to be further investigated in the field include retail energy management in presence of renewable energy resources, storage devices, DRPs and PHEVAs. Moreover, further researches are required to study the retail problem in the perfect market with pure competition.

\section{References}

1. Shahidehpour M, Yamin H, Li Z (2002) Market operations in electric power systems. Wiley, New York

2. Deng SJ, Oren SS (2006) Electricity derivatives and risk management. Energy 31:940-953

3. Kirschen Daniel S (2003) Demand-side view of electricity markets. IEEE Trans Power Syst 18(2):520-527

4. Morales JM, Conejo AJ, Madsen H, Pinson P, Zugno M (2014) Integrating renewable in electricity markets. Springer Publications, New York

5. Kirschen DS, Strbac G (2004) Fundamentals of power system economics. Wiley, Amsterdam

6. Stoft S (2002) Power system economics. IEEE Press and Wiley Publications

7. Conejo AJ, Carrión M, Morales JM (2010) Decision making under uncertainty in electricity market. Springer Publications, New York

8. Hatziargyriou N (2014) Microgrids: architectures and control. IEEE Press and Wiley Publications

9. DOE Report. Benefits of demand response in electricity markets and recommendations for achieving them, 2006 (http:// westvirginia.sierraclub.or)

10. Mariasiu F, Moldovanu D, Iclodean C (2015) Electric and plugin hybrid vehicles: advanced simulation methodologies. Springer Publications, New York, p Varga, B O

11. Golmohamadi H, Ramezani M, Bashian A, Falaghi H (2014) Riskbased maintenance scheduling of generating units in the deregulated environment considering transmission network congestion. J Modern Power Syst Clean Energy 2(2):150-162

12. Gil HA, Lin J (2013) Wind power and electricity prices at the PJM market. IEEE Trans Power Syst 28(4):3945-3953
13. Wehinger LA, Hug-Glanzmann G, Galus MD, Andersson G (2013) Modeling electricity wholesale markets with model predictive and profit maximizing agents. IEEE Trans Power Syst 28(2):868-876

14. Nguyen DT, Le LB (2014) Optimal bidding strategy for microgrids considering renewable energy and building thermal dynamics. IEEE Trans Smart Grid 5(4):1608-1620

15. Shi L, Luo Y, Tu GY (2014) Bidding strategy of microgrid with consideration of uncertainty for participating in power market. Electr Power Energy Syst 59:1-13

16. Charwand M, Moshavash Z (2014) Midterm decision-making framework for an electricity retailer based on information gap decision theory. Electr Power Energy Syst 63:185-195

17. García-Bertrand R (2013) Sale prices setting tool for retailers. Trans Smart Grid 4(4):2028-2035

18. Ahmadi A, Charwand M, Aghaei J (2013) Risk-constrained optimal strategy for retailer forward contract portfolio. Electr Power Energy Syst 53:704-713

19. Nazari M, Foroud AA (2013) Optimal strategy planning for a retailer considering medium and short-term decisions. Electr Power Energy Syst 45:107-116

20. Herranz R, San Roque AM, Villar J, Campos FA (2012) Optimal demand-side bidding strategies in electricity spot markets. IEEE Trans Power Syst 27(3):1204-1213

21. Mashhour E, Moghaddas-Tafreshi SM (2011) Bidding strategy of virtual power plant for participating in energy and spinning reserve markets-Part i: problem formulation. IEEE Trans Power Syst 26(2):949-956

22. Mashhour E, Moghaddas-Tafreshi SM (2011) Bidding strategy of virtual power plant for participating in energy and spinning reserve markets-Part II: numerical analysis. IEEE Trans Power Syst 26(2):957-964

23. Hatami A, Seifi H, Sheikh-El-Eslami MK (2011) A stochasticbased decision-making framework for an electricity retailer: timeof-use pricing and electricity portfolio optimization. IEEE Trans Power Syst 26(4):1808-1816

24. Hajati M, Seifi H, Sheikh-El-Eslami MK (2011) Optimal retailer bidding in a DA market - a new method considering risk and demand elasticity. Energy 36:1332-1339

25. Yau S, Kwon RH, Rogers JS, Wub D (2011) Financial and operational decisions in the electricity sector: contract portfolio optimization with the conditional value-at-risk criterion. Int J Prod Econ 134:67-77

26. Karandikar RG, Khaparde SA, Kulkarni SV (2010) Strategic evaluation of bilateral contract for electricity retailer in restructured power market. Electr Power Energy Syst 32:457463

27. Mahmoudi-Kohan N, Parsa Moghaddam M, Sheikh-El-Eslami MK, Shayesteh E (2010) A three-stage strategy for optimal price offering by a retailer based on clustering techniques. Electr Power Energy Syst 32:1135-1142

28. Kettunen J, Salo A, Bunn DW (2010) Optimization of electricity retailer's contract portfolio subject to risk preferences. IEEE Trans Power Syst 25(1):117-128

29. Carrión M, Arroyo JM, Conejo AJ (2009) A bilevel stochastic programming approach for retailer futures market trading. IEEE Trans Power Syst 24(3):1446-1456

30. Hatami AR, Seifi H, Sheikh-El-eslami MK (2009) Optimal selling price and energy procurement strategies for a retailer in an electricity market. Electr Power Syst Res 79:246-254

31. Nojavan S, Mohammadi-Ivatloo B, Zare K (2015) Optimal bidding strategy of electricity retailers using robust optimisation approach considering time-of-use rate demand response programs under market price uncertainties. IET Gener Transm Distrib 9(4):328-338 
32. Shafie-khah M, Catalão JPS (2015) A stochastic multi-layer agent-based model to study electricity market participants behavior. IEEE Trans Power Syst 30(2):867-881

33. Wei W, Liu F, Mei S (2015) Energy pricing and dispatch for smart grid retailers under demand response and market price uncertainty. IEEE Trans Smart Grid 6(3):1364-1374

34. Carrión M, Conejo AJ, Arroyo JM (2007) Forward contracting and selling price determination for a retailer. IEEE Trans Power Syst 22(4):2105-2114

35. Soroudi A, Rabiee A (2013) Optimal multi-area generation schedule considering renewable resources mix: a real-time approach. IET Gener Transm Distrib 7(9):1011-1026

36. Hessam G, Reza K, Hassanpour A, Masoud D (2015) Optimization of green energy portfolio in retail market using stochastic programming. North American Power Symposium (NAPS):1-6

37. Holmberg DG, Hardin DB, Bushby ST (2014) Facility Smart Grid Interface and a Demand Response Conceptual Model. National Institute of Standards and Technology US Department of Commerce

38. Williamson SS, auth. Energy Management Strategies for Electric and Plug-in Hybrid Electric Vehicles [1 ed.]

39. Siano P (2014) Demand response and smart grids-a survey. Renew Sust Energ Rev 30:461-478

40. Albadi MH, El-Saadany EF (2008) A summary of demand response in electricity markets. Electr Power Syst Res 78(11):1989-1996

41. de Sa Ferreira R, Barroso LA, Rochinha Lino P, Carvalho MM, Valenzuela $\mathrm{P}$ (2013) Time-of-use tariff design under uncertainty in price-elasticities of electricity demand: a stochastic optimization approach. IEEE Trans Smart Grid 4(3):2285-2295

42. Zhang X (2014) Optimal Scheduling of Critical Peak Pricing Considering Wind Commitment. IEEE Trans Sustainable Energy 5(2):637-645

43. Namerikawa T, Okubo N, Sato R, Okawa Y, Ono M (2015) Real-time pricing mechanism for electricity market with builtin incentive for participation. IEEE Trans Smart Grid 6(6):27142724

44. Vandael S, Claessens B, Hommelberg M, Holvoet T, Deconinck G (2013) A scalable three-step approach for demand side management of plug-inhybrid vehicles. IEEE Trans Smart Grid 4(2):720-728

45. Khojasteh M, Jadid S (2015) A two-stage robust model to determine the optimal selling price for a distributed generation-owning retailer. Int Trans Electr Energy Syst 25(12):3753-3771

46. Kilkki O, Alahaivala A, Seilonen I (2015) Optimized control of price-based demand response with electric storage space heating. IEEE Trans Ind Inform 11(1):281-288

47. Jia L, Tong L (2016) Renewables and Storage in Distribution Systems: Centralized vs. Decentralized Integration IEEE Journal on Selected Areas in Communications, Article first published online

48. Yu M, Hong SH (2016) A real-time demand-response algorithm for smart grids: a stackelberg game approach. IEEE Trans Smart Grid 7(2):879-888

49. Mahmoudi N, Eghbal M, Saha TK (2014) Employing demand response in energy procurement plans of electricity retailers. Int $\mathbf{J}$ Electr Power Energy Syst 63:455-460

50. Badri A, Lonbar KH (2016) A short-term optimal decision making framework of an electricity retailer considering optimized EVs charging model International Transactions on Electrical Energy Systems Article first published online: 8 JAN

51. Mohammadi-Ivatloo B, Zareipour H, Amjady N, Ehsan M (2013) Application of information-gap decision theory to riskconstrained self-scheduling of GenCos. IEEE Trans Power Syst 28:1093-1102

52. Golmohamadi H, Keypour R (2017) Application of robust optimization approach to determine optimal retail electricity price in presence of intermittent and conventional distributed generation considering demand response journal of control. Autom Electron Syst 28(5):664-678

53. Kazemi M, Zareipour H, Ehsan M, Rosehart WD (2017) A robust linear approach for offering strategy of a hybrid electric energy company. IEEE Trans Power Sys 32(3):1949-1959

54. Wei W, Liu F, Mei S (2015) Energy pricing and dispatch for smart grid retailers under demand response and market price uncertainty. IEEE Trans Smart Grid 6(3):1364-1374

55. Nojavan S, Mehdinejad M, Zare K, Mohammadi-Ivatloo B (2015) Energy procurement management for electricity retailer using new hybrid approach based on combined BICA-BPSO. Electr Power Energy Syst 73:411-419

56. Mehrotra S, Papp D (2013) Generating moment matching scenarios using opti- mization techniques. SIAM J Optim 23(2):963999

57. Rubio F, Mestre X, Palomar DP (2012) Performance analysis and optimal selection of large minimum VariancePortfolios under estimation risk. IEEE J Selected Topic Signal Process 6(4):337350

58. Yang L (2012) Study on cumulative residual entropy and variance as risk measure. In: 2012 Fifth International Conference on Business Intelligence and Financial Engineering (BIFE), pp 210213

59. Akcay Y, Yalcin A (2010) Optimal portfolio selection with a shortfall probability constraint: evidence from alternative distribution functions. J Financ Res 33(1):77-102

60. Ogryczak W, Ruszczynski A (1999) From stochastic dominance to mean-risk models: semi deviations as risk measures. Eur J Oper Res 116(1):33-50

61. Artzner P, Delbaen F, Eber JM, Heath D (1999) Coherent measures of risk. Math Finance 9(3):203-228

62. Rockafellar RT, Uryasev S (2000) Optimization of conditional value-at-risk. J Risk 2(3):21-41

63. Rockafellar RT, Uryasey S (2002) Conditional value-at-risk for general loss distributions. J Banking Finance 26(7):1443-1471

64. Herring R, Diebold FX, Doherty NA (2010) The known, the unknown, and the unknowable in financial risk management: measurement and theory advancing practice. Princeton University Press, Princeton, p 347

65. Oral C, Cenkakkaya G (2015) Cash flow at risk: a tool for financial planning. Proc Econ Finance 23:262-266

66. www.energy.gov, US department of energy, DEO

67. Nguyen DT, Le LB (2015) Risk-constrained profit maximization for microgrid aggregators with demand response. IEEE Trans Smart Grid 6(1):135-146

68. Zhang D, Li S, Zeng P, Zang C (2014) Optimal microgrid control and power-flow study with different bidding policies by using power world simulator. IEEE Trans Sustainable Energy 5(1):282292

69. Chen C, Wang J, Kishore S (2014) A distributed direct load control approach for large-scale residential demand response. IEEE Trans Power Syst 29(5):2219-2228

70. Caves DW, Herriges JA, Hanser P, Windle RJ (1988) Load impact of interruptible and curtailable rate programs: evidence from ten utilities [tariff incentives]. IEEE Trans Power Syst 3(4):17571763

71. Sahebi MM, Duki EA, Kia M, Soroudi A, Ehsan M (2012) Simultanous emergency demand response programming and unit commitment programming in comparison with interruptible load contracts. IET Gener Transm Distrib 6(7):605-611

72. (2006) US Department of Energy, Benefits of Demand Response in Electricity Markets and Recommendations for Achieving them, Report to the United States Congress. available online: http://eetd. lbl.gov 
73. Kim D-M, Kim J-O (2012) Design of emergency demand response program using analytic hierarchy process. IEEE Trans Smart Grid 3(2):635-644

74. Vasileva E, Viljainen S Capacity market as an incentive for demand response in Russia 11th International Conference on the European Energy Market, 2014, pp 1-5

75. Aghaei J, Alizadeh M-I (2014) Robust n-k contingency constrained unit commitment with ancillary service demand response program. IET Gener Transm Distrib 8(12):1928-1936

76. de Sa Ferreira R, Barroso LA, Rochinha Lino P, Carvalho MM, Valenzuela $\mathrm{P}$ (2013) Time-of-use tariff design under uncertainty in price-elasticities of electricity demand: a stochastic optimization approach. IEEE Trans Smart Grid 4(4):2285-2295

77. Gellings C, Chamberlin J (1988) Demand side management: concepts and methods, the fairmont press inc. US

78. Aghaei J, Alizadeh M-I (2013) Critical peak pricing with load control demand response program in unit commitment problem. IET Gener Transm Distrib 7(7):681-690

79. Jazayeri P, Schellenberg A, Rosehard WD, Doudna J, Widergren S, Lawrence D, Mickey J, Jones S (2005) A survey of load control programs for price and system stability. IEEE Trans Power Syst 20(3):1504-1509

80. Charles River Associates, Primer on Demand-Side Management with an Emphasis on Price-Responsive Programs, Report prepared for The World Bank, Washington, DC, CRA No. D06090, available online: http://www.worldbank.org

81. Chen Z, Wu L, Fu Y (2012) Real-time price-based demand response management for residential appliances via stochastic optimization and robust optimization. IEEE Trans Smart Grid 3(4):1822-1831

82. Widergren S, Marinovici C, Berliner T, Graves A Real time pricing demand response in operations IEEE Power and Energy Society General Meeting, 2012, 1-5

83. Yoon JH, Baldick R, Novoselac A (2014) Dynamic demand response controller based on Real-Time retail price for residential buildings. IEEE Trans Smart Grid 5(1):121-129

84. Mengmeng Y, Seung Ho Hong A (2016) Real-Time DemandResponse Algorithm for smart grids. A Stackelberg Game Approach IEEE Transactions on Smart Grid 7(2):879-888

85. Kazemi M, Zareipour H, Ehsan M, Rosehart WD (2017) A robust linear approach for offering strategy of a hybrid electric energy company. IEEE Trans Power Syst 32(3):1949-1959

86. Sekizaki S, Nishizaki I, Hayashida T (2016) Electricity retail market model with flexible price settings and elastic price-based demand responses by consumers in distribution network. Int $\mathrm{J}$ Electr Power Energy Syst 81:371-386

87. Song M (2017) Mikael amelin purchase bidding strategy for a retailer with flexible demands in Day-Ahead electricity market IEEE transactions on power systems, vol 32 (3)

88. Dehghanpour K, Nehrir H, Sheppard J, Kelly N (2017) Agent-Based Modeling of Retail Electrical Energy Markets With Demand Response. IEEE Transactions on Smart Grid. https://doi.org/10.1109/TSG.2016.2631453

89. Chen T, Pourbabak H, Liang Z, Su W (2017) An integrated eVoucher mechanism for flexible Loads in real-time retail electricity market. IEEE Access 5:2101-2110 